\title{
THE DETERMINATION OF MOISTURE IN FUEL.
}

\author{
BY \\ J. A. P. CRISFIELD, \\ Engineer of Construction, United Gas Improvement Company.
}

WHEN purchasing and utilizing coke and coal, the presence of moisture in the material purchased is objectionable for at least two reasons: First, the water is purchased and paid for as carbon; and, second, the water so purchased necessitates the combustion of some of the carbon to drive it off from the fuel bed. Thus we are not only paying for a worthless material as good carbon, but we are penalized as well.

Bituminous coal, and frequently coke, is received at destination in open cars of the gondola type, and in transit is liable to be soaked by heavy rains, sleet, or snow. Usually the shipment is paid for by railroad weights, and if the car was weighed before the contents were water-soaked, the purchaser suffers no loss from the first objection named; he must, however, still encounter the cost of boiling off the water accumulated in transit.

In order to give an idea of the amount of water which somie well-known fuels will absorb, samples of oven coke, runof-mine steam coal, and Fairmount gas coal were subjected to the following test (see Appendix, No. I) :

The fuels were wet down with a hose, drained by being placed in perforated galvanized iron pails, and weighed. These pails were then hung in a normal atmosphere at a temperature of $70^{\circ} \mathrm{F}$. and weighed at intervals of one day until ten days had expired. The details of this test prove that in the case of oven coke the wet sample lost I 4.6 per cent. of its weight, due to the evaporation of the moisture which it originally contained. With the steam coal, the loss was I 3.3 per cent.; but with the Fairmount, screened gas coal, the aggregates consisting of clean cubes about egg size, the contained moisture was only 2.2 per cent. Other tests of retort coke from coal gas plants show that this coke will absorb water to the extent of 22 per cent. of its dry weight if exposed to rain.

It is evident, therefore, that unless we have some knowledge 
of the content of moisture in the fuel, we may pay is per cent. more for a ton of carbon in the case of wet fuel than we do in the case of dry fuel. The significance of this possibility becomes more apparent when we consider the case of a carburetted water gas plant manufacturing I0,000,000 cubic feet of gas a day, with a consumption of I 50 tons of coke daily. The value of this dry coke at current prices is $\$ 675$. If, during the process of quenching, or at any time previous to weighing, it has absorbed Io per cent. moisture, the increased cost to the gas company over and above what it would pay for dry coke is $\$ 75$ a day, or, in a year of 365 days, $\$ 27,375$. In addition to this expense, the cost of boiling off this water from the fuel after it is put into the cupolas will be, in the case of a plant discharging the stack gases at a temperature of ${ }^{2} 500^{\circ} \mathrm{F}$., 2 per cent. of the total fuel consumed. This would add another expense of $\$$ I $3.5^{\circ}$ per day, or $\$ 4,927.5^{\circ}$ yearly.

Referring again to the test of the various samples of fuel, when soaked with water and allowed to dry, it will be noted that there was a gradual dissipation of the moisture from the start of the test until the end. In other words, if a sample of wet coke or coal is selected at the mines or at the car and transported any appreciable distance or for any considerable time, there will be, if protected from further wetting, a loss of moisture in the sample. To illustrate this, I quote from a letter received from Mr. C. J. Ramsburg, Assistant Engineer of Works of the Philadelphia Gas Works:

"So far, the use of the moisture determinator has been restricted to the testing of coke receipts, in which we have proved that the laboratory analysis of the coke is no criterion of the condition of the coke as received by us. For example, on October $3 \mathrm{~d}$ a barge of coke was received, the average sample of which was taken during the unloading, and, tested in the moisture determinator, showed I1.6 per cent. moisture. The analysis of the sample taken at the same time, when conveyed to the laboratory, crushed and sampled according to the usual laboratory system, showed only 2.I per cent. moisture."

Numerous other instances of the same general nature could be cited.

Where very high guarantees are made of the consumption of carbon in water gas apparatus, the determination 
of the water in the fuel becomes a very important matter. For example, the presence of Io per cent. of moisture may readily result in a failure to obtain the guarantee, not only because it interferes with the proper working of the apparatus, but because it is weighed into the apparatus as carbon. Under these circumstances, great difficulty has been experienced in obtaining the content of moisture in the fuel actually charged into the machine, on account of the fact that the laboratory is frequently at a distance from the generating house and considerable time elapses between the taking of the sample and its analysis in the laboratory. These conditions always operate against the guarantor of results, as there is invariably a loss of moisture, where much is present during the transportation and handling of the sample, for which the operator gets no credit. In the standard method of determining moisture in coal and coke, opportunity is also offered for the escape of moisture to the atmosphere after the sample is received at the laboratory and before the determination actually begins. Usually the finely-ground sample is placed in an open porcelain or platinum crucible, weighed, and dried for one hour in any good form of air bath. Lpon removal from the oven, the crucible is covered and cooled in a desiccator and again weighed. The loss in weight gives the moisture. It will be noted that before the initial weight is taken the sample has been selected on the generator house floor, transported to the laboratory, and finely ground. During all this period there is a continual loss of moisture, the amount depending somewhat upon the humidity of the atmosphere.

It was on account of the difficulties described above that an effort was made to devise a simple and fairly accurate means of making moisture determinations at the place where the fuel is consumed. The result is the moisture determinator as shown assembled in Fig. I and in section in Fig. 2. In this instrument a steam jacket is used to drive off the moisture, the temperature of the jacket being cletermined by the steam pressure, and maintained at such a point that, while the moisture is driven off, the volatile combustible will be retained in the fuel chamber. $A$ is the fuel chamber in which is deposited the sample of fuel to be examined for moisture. Its volume is such as conveniently to hold the ample sample of one pound of the fuel. $B$ is a graduated glass tube surrounded by a reservoir $C$ containing VOL. CLXXII. No. IO3T-36 
cool water, which latter may be introduced at $I$ and be removed at $O$, thus forming a condenser. The graduations of the tube $B$ are of such magnitude that when I per cent. by weight of the sample is driven off in the form of moisture and condensed in the tube the volume of the condensed water vapor driven off

FIG. I.

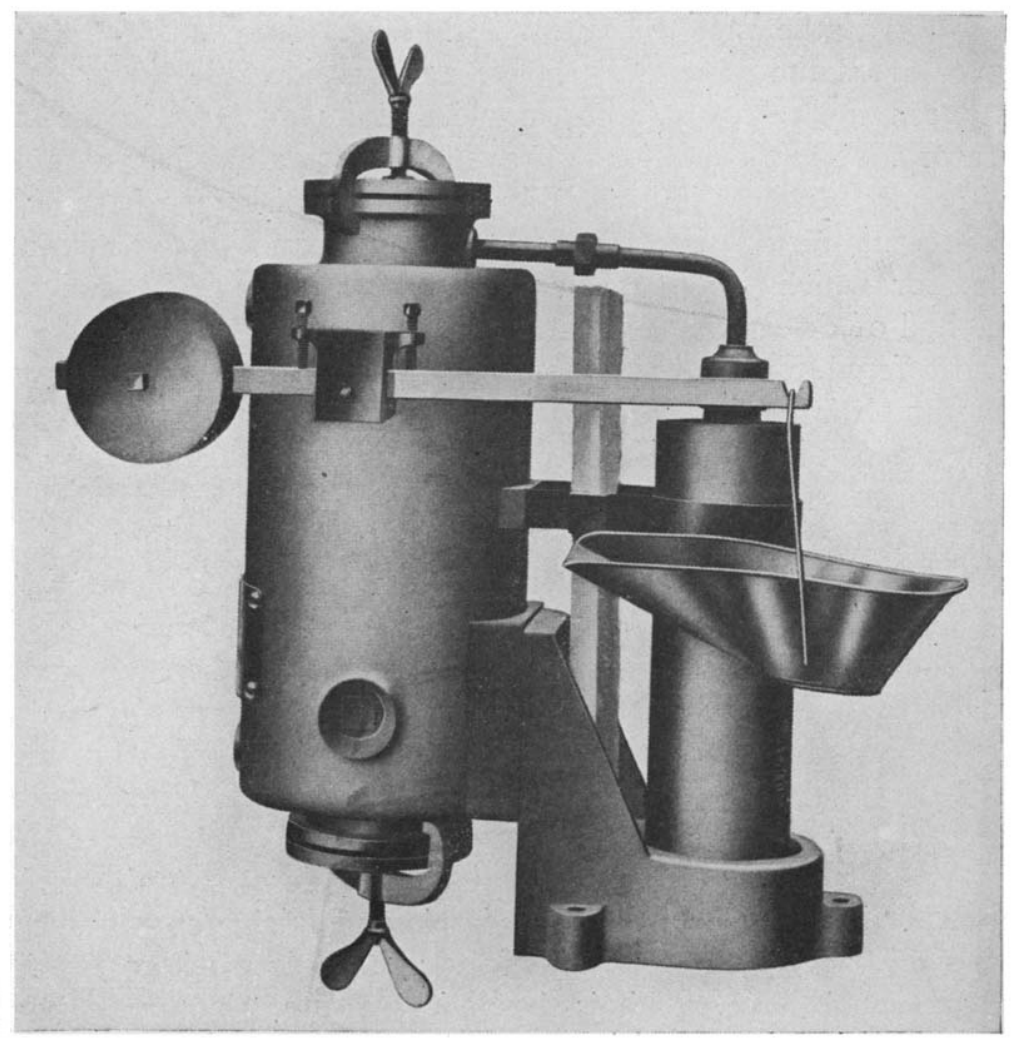

will just equal the volume between any two graduations on the tube. Around the chamber $A$, forming a jacket, is the annular space $J$. Into this space steam at any desired temperature is introduced at $S$ and discharged at $R . M$ and $N$ are means for filling and emptying the chamber $A$, and $K$ is a ground joint union which permits the graduated tube $B$ to be disconnected and emplied after the determination is completed. The apparatus is operated as follows: 
The determinator may be erected on any convenient wall or table, preferably as close as possible to the point where the fuel is being consumed, thus eliminating to a great degree any change in the moisture content in the sample between the time the sample is taken and the time the moisture content is determined.

\section{FIG, 2.}

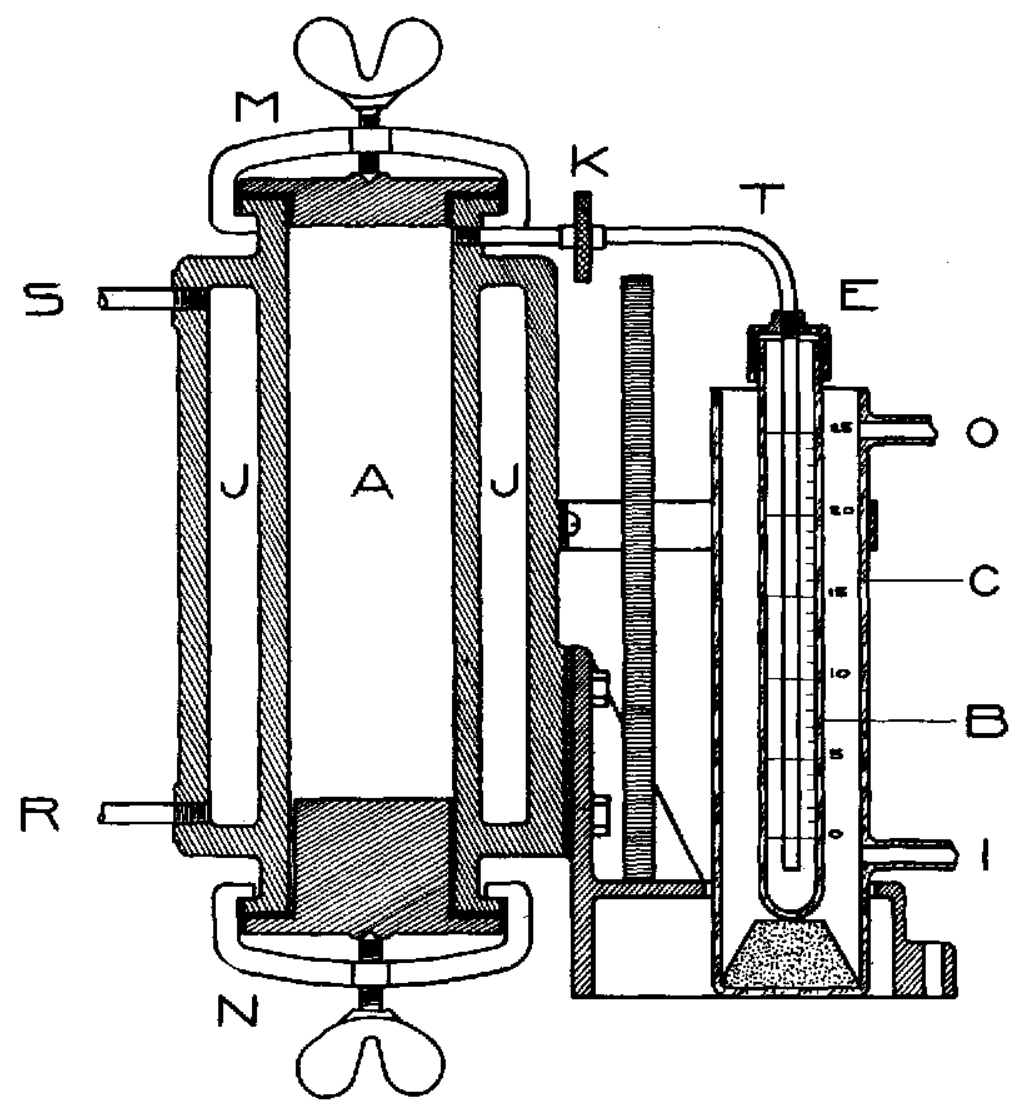

A balance shown in Fig. I is provided with the determinator, by the aid of which one pound of the fuel is introduced into the chamber $A$. Steam is then turned on the jacket $J$, and by the aid of a pressure gauge on the pipe $S$ the temperature is maintained at any convenient degree, preferably at $20^{\circ} \mathrm{F}$, as at this temperature the water may be driven off 
without the volatilization of any of the hydro-carbon vapors. A cock on the discharge pipe $R$ should be left slightly open so that any water condensed in the chamber may be carried off, and thus prevent it from affecting the temperature of the jacket. Previous to turning on the steam, water circulation has been started through the receptacle $C$ by means of the pipes $I$ and $O$; also, sufficient water has been introduced through the hole $E$ to bring up the level in the tube $B$ to the zero mark. Upon the turning on of the steam through the pipe $S$ the determination begins and the instrument may be left without any attention for the space of an hour, when it will be found that practically all of the moisture is driven off from the sample and appears in the tube $B$ as water, in per cents. of the original weight of the sample.

In addition to its other merits, the apparatus possesses the following two very important ones:

First: In its use but one weighing-that of the moist sample of fuel-is necessary, and any small error in this weighing can produce only a correspondingly small error in the moisture percentage result; in the ordinary method, on the other hand, two weighings - one of the moist and one of the dry sampleare required, and even a small error in one of these weighings, and consequently in their difference, which is supposed to represent the weight of moisture, may cause a very large error in the determination of percentage of moisture.

Second: The moisture in the fuel is condensed to water, is visible, and hence its existence is indisputable.

Before this instrument was put into scrvice a calculation was made to determine theoretically what would be its characteristic error. This calculation is given in Appendix No. 2, and shows that theoretically the error should be about . I3 per cent.; that is, the true content of moisture would be .I3 per cent. greater than the indicated content, owing to the volume of the voids in the sample of fuel and of the pores of the coke itself. To check this calculation, definite quantities of moisture were added to dry samples of coke and the samples examined in the determinator, with the result that the practical error agreed with the theoretical error.

Although this instrument was devised particularly for use in 
obtaining high guarantees connected with the combustion of coke and coal, it has been found useful in various ways. For instance, in a coal gas plant where the yield of gas, ammonia, tar, etc., per pound of coal is figured in great detail, it is found that the uncertainty introduced by the presence of a variable amount of moisture is very annoying. With the use of the moisture determinator, however, this uncertainty is to a large extent eliminated. In one case it was found that the content of moisture in gas coal as weighed into the bins averaged as high as 9 per cent. for a period of some months. If this content of moisture had not been known, the poor results from the use of such coal would have widely misled the operating engineer.

New uses for this instrument are constantly being suggested, among them the determination of water in metallic ores, and water and light oils in tar. $\Lambda$ t present it does not seem practicable for everyone to purchase coal on a B. T. U. basis, but the United States Government has adopted this practice, and, as it is without doubt the equitable way of purchasing fuel, we may expect before many years to see it generally adopted. In this case the determination of the moisture in the shipment purchased is of equal importance with the determination of ash and other impurities, and the field of usefulness for the moisture cleterninator will probably be greatly broadened.

Appendix No. I.

A. Camden oven coke egg size.

Weight of dry sample........................... $9.9 \mathrm{lbs}$.

B. Quemahoning boiler coal, run-of-mine.

Weight of dry sample......................... I6.7 lbs.

C. Fairmount gas coal screened; egg size.

Weight of dry sample.

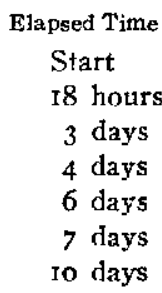

Elapsed Time

Start

I8 hours

3 days

4 days

6 days

ro days

\begin{tabular}{ccc}
\multicolumn{3}{c}{ Percent of Moisture } \\
A. & B. & \multicolumn{1}{c}{ C. } \\
I4.6 & I3.3 & 2.2 \\
II.3 & 9.6 & 1.2 \\
7.4 & 5.9 & .9 \\
6.6 & 4.6 & .7 \\
4.5 & 2.3 & .6 \\
3.3 & 1.7 & .6 \\
2.5 & I.3 & .6
\end{tabular}




\section{ApPENDIX No. 2.}

\section{Moisture determinator.}

Chamber $=2-z^{\prime \prime}$ diam. $\times 12^{n}=6.4918$ sq. in. $\times 12^{\prime \prime}=.0451$ cu. ft.

Capacity of Chamber: Allowance 37 per. cent. $=$ voids in coke $=.045 \mathrm{I}$ cu. $\mathrm{ft} . \mathrm{X} .37=.0167 \mathrm{cu} . \mathrm{ft}$. - volume containing moisture at finish.

$$
\begin{aligned}
& 212^{\circ} \quad \mathrm{F} \text {. } \\
& 459.480 \mathrm{lbs} \text {. press, }=95 \mathrm{lbs} \text {, absolute }=323.9^{\circ} \mathrm{F} \text {. } \\
& 671.4^{\circ} \mathrm{F} \text {. Absolute temp. } \\
& \frac{459.4}{7^{83.3^{\circ}}} \text { F. Abs. }
\end{aligned}
$$

.0167 cu. ft. $\times \frac{671.4}{783 \cdot 3}=.0143$ cu. it. steam.

1 cu. ft. steam, atmospheric pressure $=.03794 \mathrm{lbs}$.

$.0143 \times .03794=.0005425$ lbs. steam remaining at finish of operation.

I cu. in. $\mathrm{H}_{2} \mathrm{O}$ at $60^{\circ} \mathrm{F},=\mathrm{I} 6,4 \mathrm{cu}$. centimetres.

I cu. in. $\mathrm{H}_{2} \mathrm{O}$ at $60^{\circ} \mathrm{F} .=.036 \mathrm{I}$ Jbs.

.0005425 lbs. divided by $.0361=.01503$ cubic inches.

.01503 cu. in. $\times 16.4=.2465$ c.c. $\mathrm{H}_{2} \mathrm{O}$ remaining at finish, due to voids.

Coke as per sample $=\mathbf{5 0}$ per. cent. porosity.

37 per. cent. voids.

87 per. cent. total.

$.045 \mathrm{I} \mathrm{cu.} \mathrm{ft.} \mathrm{capacity} \times .87=0.039^{2} 37 \mathrm{cu} . \mathrm{ft} .=$ volume due to porosity and voids $=\begin{gathered}.039237 \\ .0167\end{gathered}$ or 2.35 times the above.

$.0005425 \mathrm{lbs}$. steam remaining $\times 2.35=.001275 \mathrm{lbs}$. steam $=\frac{.001275}{.036 \mathrm{I}}=$ $.0353 \mathrm{I} \mathrm{cu}$ in.

.03531 cu. in. $\times$ I6.4 c.c. $=.579$ c.c. $\mathrm{H}_{2} \mathrm{O}$ remaining.

I c.c. $\mathrm{H}_{2} \mathrm{O}$ at $60^{\circ} \mathrm{F} .=1.00 \mathrm{I}$ grains $X .579=.5795$ grains.

Assumption I lb. coke $=453.6$ grains gross weight $\frac{.5795}{453.6}=.0012775=$ . $\mathbf{2} 775$ per cent. $=$ Loss.

The Resistance of Iron to Rust in Concrete. ANov. (Rev. Scientifique, xlix, $\mathbf{r}, 23$.) -An old building in Hamburg was recently demolished, from which the behavior of iron enclosed in concrete can be judged. This was an old gasometer, the foundations of which rested on several pillars. The iron anchors were immersed in cement grouted to a good thickness. The 60 bars, each $2 \frac{1}{2}$ metres long, which formed the anchors, were examined, and were found to be perfectly well preserved. They still showed their outer bluish skin and no trace of rust. This gasometer was built between 1852 and 1855 , so the iron bars had been fully 50 years in the concrete. This protection from rust can be explained by the fact that the dampening of the concrete had produced a strongly alkaline reaction, and that iron, when surrounded by alkali, is inoxidizable. 